\title{
BAMBOO FIBER REINFORCED BINDERLESS GREEN COMPOSITES FROM STEAM-EXPLODED BAMBOO POWDER
}

\author{
HITOSHI TAKAGI* \\ Institute of Technology and Science, The University of Tokushima, \\ 2-1 Minamijosanjima-cho, Tokushima, 770-8506, Japan \\ takagi@me.tokushima-u.ac.jp (*corresponding author) \\ GOSHI TAKEICHI \\ Graduate School of Advanced Technology and Science, The University of Tokushima, \\ 2-1 Minamijosanjima-cho, Tokushima, 770-8506, Japan \\ ryty_gn@yahoo.co.jp
}

\begin{abstract}
In this paper, we attempted to prepare the binderless green composite using bamboo fiber and steam-exploded bamboo powder as matrix. The influence of molding conditions on their tensile behavior was investigated by changing the molding temperature, pressure and time. Except for the composites molded at low temperatures from $100^{\circ} \mathrm{C}$ to $120^{\circ} \mathrm{C}$, their tensile strength decreased with increasing the molding temperature. When the molding time increased, their tensile strength decreased. Average tensile strength of the binderless bamboo green composite molded at $120^{\circ} \mathrm{C}$ and $10 \mathrm{MPa}$ for $10 \mathrm{~min}$ was $170 \mathrm{MPa}$. The decreases in tensile strength of binderless composites molded at temperatures higher than $120^{\circ} \mathrm{C}$ may be responsible for the strength drop of the reinforcing bamboo fiber derived from thermal decomposition. In order to obtain detailed information about the adhesion behavior of bamboo powder and bamboo fiber, photomicrographs were taken of the fracture surfaces of the composites. The results show that molding condition, especially molding temperature, has a great effect on the mechanical properties of bamboo fiber reinforced binderless green composites.
\end{abstract}

Keywords: Binderless composites; bamboo; green composites; steam-explosion.

\section{Introduction}

Nowadays we have been using variety of plastics and polymer composites, such as polypropylene, polyethylene, glass fiber reinforced plastics (GFRP), etc. for many applications. However most of these synthetic polymeric materials are made from petroleum and/or coal, which are typical of the fossil fuels and have serious supply challenges. From these circumstances the research and development of bio-based materials including green composites and bio-composites are conducting in North America $^{1,2}$, Europe $^{3,4}$, and East Asia ${ }^{5-9}$.

Typical of the green composites are composed of biodegradable resin and natural plant fiber. The higher cost of the biodegradable resin such as poly-lactic acid (PLA) and 
polyhydroxyalkanoate (PHA) prevent from applying the green composites to commercial products. The use of natural fiber contributes not only to increase in the mechanical performance but also to decrease the total materials cost, because most of the natural fiber is not expensive. However, there is limitation to lower the cast of the green composites.

Therefore, the authors group has been researching on the development of new biobased composites without using any synthetic resin ${ }^{10-12}$. Mori and Takagi have developed resinless bamboo composites, in which the plastic deformable parenchyma cells attached on the bamboo fiber was utilized as a matrix phase ${ }^{10,11}$. In addition, Takagi et al. made all bamboo composites; namely resinless, from hot-pressed bamboo column ${ }^{12}$. These results indicate that parenchyma cells of steam-exploded bamboo can be successfully used as matrix phase.

Now we are aiming to fabricate new biomass-based composites in which all raw materials are derived from bamboo. In this study we examined the effect of molding conditions on their mechanical properties.

\section{Experimental Method}

\subsection{Materials}

As a matrix material, we used steam-exploded bamboo powder. "Moso" bamboo (Phyllostachys pubescens) cultivated in Tokushima, Japan was steam-exploded in the following conditions: one time explosion after a steam treatment at $170^{\circ} \mathrm{C}$ and $980 \mathrm{kPa}$ for 40 min., and then seven times explosions after a steam treatment at $170^{\circ} \mathrm{C}$ and $980 \mathrm{kPa}$ for $6 \mathrm{~min}$. Finally the steam-exploded bamboo powder was pulverized for 30 seconds by using a high-power blender (WB-1; Osaka Chemical Co. Ltd., Japan). This pulverization was repeated once again (totally one minute treatment).

Unidirectional bamboo fiber was used as reinforcement. The bamboo fiber was also extracted from "Moso" bamboo by using the steam explosion method". The conditions for the steam explosion were the same as those of bamboo powder as described above.

\subsection{Fabrication of composites}

The unidirectional bamboo fiber reinforced green composites were fabricated by a hotpressing method. The steam-exploded bamboo powder and bamboo fiber were alternately stacked in a metallic mold as follows: $0.5 \mathrm{~g}$ powder $/ 0.3 \mathrm{~g}$ fiber $/ 0.5 \mathrm{~g}$ powder $/ 0.4 \mathrm{~g}$ fiber/0.5 g powder $/ 0.3 \mathrm{~g}$ fiber $/ 0.5 \mathrm{~g}$ powder. The sample size of composites molded was approximately $100.0 \mathrm{~mm} \times 10.0 \mathrm{~mm} \times 2.5 \mathrm{~mm}$, and the volume fraction of bamboo fiber was $33 \%$. In order to examine the effect of molding temperature on the mechanical properties of the composites, the molding temperature was changed from $100^{\circ} \mathrm{C}$ to $160^{\circ} \mathrm{C}$. Other molding conditions; namely molding pressure of $10 \mathrm{MPa}$ and molding time of 10 min., were determined from the results obtained in preliminary experiments. 


\subsection{Tensile tests and observation of composites}

Quasi-static tensile tests were carried out using a universal test machine (Model 5567; Instron Corp., USA) to evaluate the mechanical properties of the composites as well as heat-treated bamboo fiber. The tensile speed for composites and bamboo fiber was $1.0 \mathrm{~mm} / \mathrm{min}$., and the gauge lengths of composites and bamboo fiber were $30.0 \mathrm{~mm}$ and $25.0 \mathrm{~mm}$, respectively. The details of fiber tensile tests are reported elsewhere ${ }^{13}$. Their fracture surface was observed using a digital microscope (VHX-600; Keyence Corp., Japan).

\section{Results and Discussion}

Figure 1 shows typical stress-strain curves of bamboo fiber reinforced binderless green composites molded at different temperatures from $100^{\circ} \mathrm{C}$ to $160^{\circ} \mathrm{C}$. It can be seen that their stress response depends on the molding temperature and that the maximum stress is closely related to fracture strain. In addition, there is a nonlinear relationship, indicating a knee point around $50 \mathrm{MPa}$.

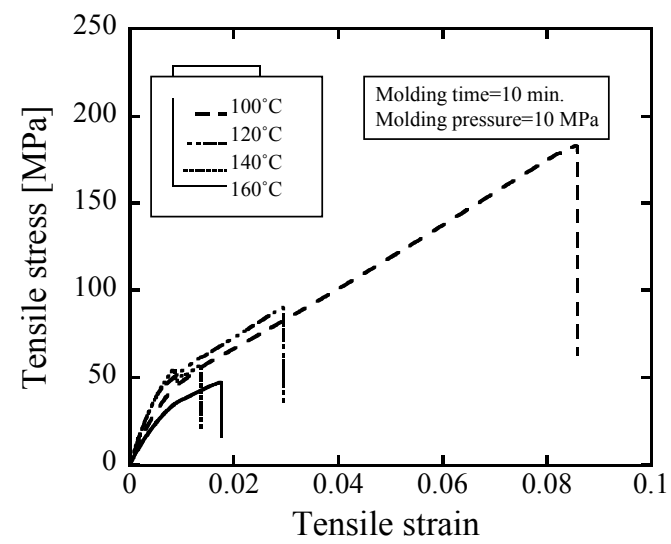

Fig. 1. Typical stress-strain curves of bamboo fiber reinforced binderless green composites.

From these curves, tensile strength and Young's modulus were measured, and plotted against the molding temperature as depicted in Figs. 2 and 3. There is a peak at $120^{\circ} \mathrm{C}$, and the tensile strength decreases with increasing molding temperature above $120^{\circ} \mathrm{C}$. On the other hand, Young's modulus increases linearly, indicating that the stress transfer between bamboo fiber and matrix is enhanced as the molding temperature increases. Similar results were also reported for resinless bamboo fiber composites ${ }^{11}$.

In order to examine the strength dependence on molding temperature, we carried out tensile tests for the bamboo fiber heat-treated at different temperatures. The typical stress-strain curves of the bamboo fiber are shown in Fig. 4. It could be observed from the results that strength and fracture strain of composites were significantly altered by the heat treatment temperature. However, Young's modulus was found to be independent of heat temperature and did not change markedly. 


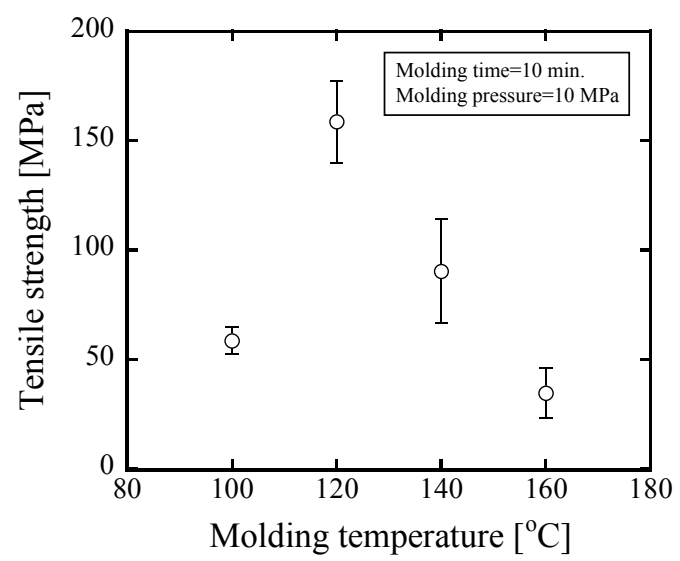

Fig. 2. Variation of tensile strength of the binderless green composites with molding temperature.

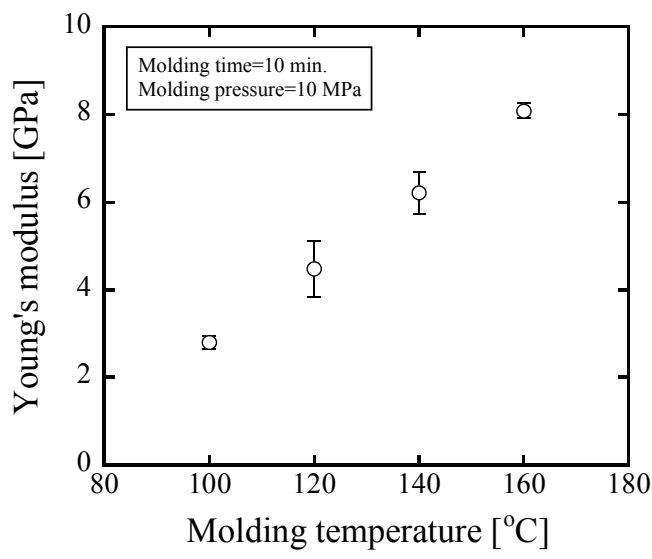

Fig. 3. Variation of Young's modulus of the binderless green composites with molding temperature.

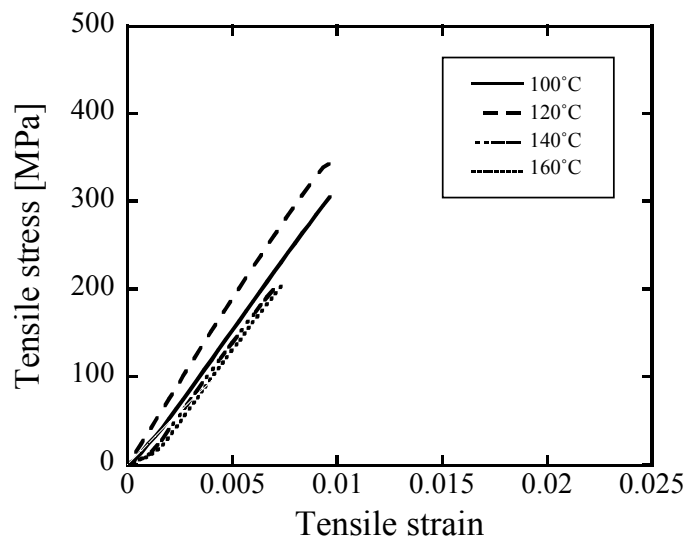

Fig. 4. Typical stress-strain curves of heat-treated bamboo fibers. 


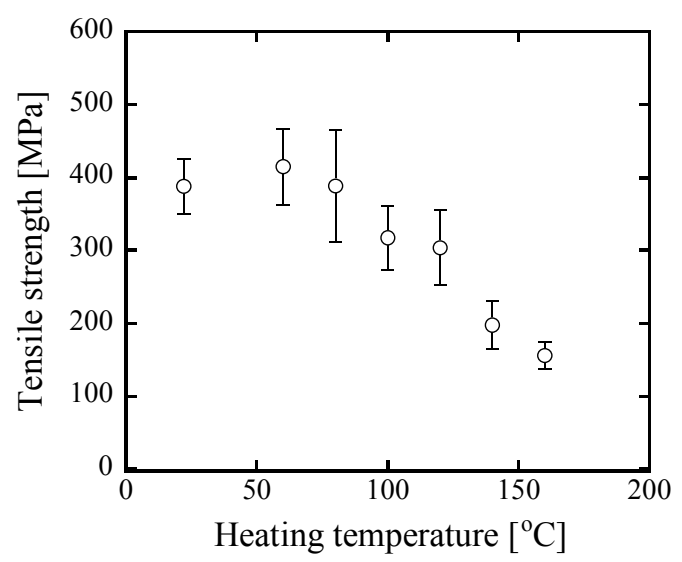

Fig. 5. Variation of tensile strength of heat-treated bamboo fiber with heating temperature.

Figure 5 shows the variation of tensile strength of heat-treated bamboo fiber. The bamboo fiber was heat-treated for $10 \mathrm{~min}$. at every temperature. Although an appreciable data scattering is observed, the tensile strength is almost invariable below $100^{\circ} \mathrm{C}$, however decreases with increasing heat-treatment temperature above $100^{\circ} \mathrm{C}$. The tensile strength of bamboo fiber heat-treated at $160^{\circ} \mathrm{C}$ is only $160 \mathrm{MPa}$, which is about $40 \%$ of the strength at room temperature. Similar strength drop after heat treatment above $100^{\circ} \mathrm{C}$ was also reported in hemp fiber ${ }^{13}$. Thus strength drop in composites fabricated at higher temperature as shown in Fig. 2 is responsible for the strength drop in reinforcing bamboo fiber.
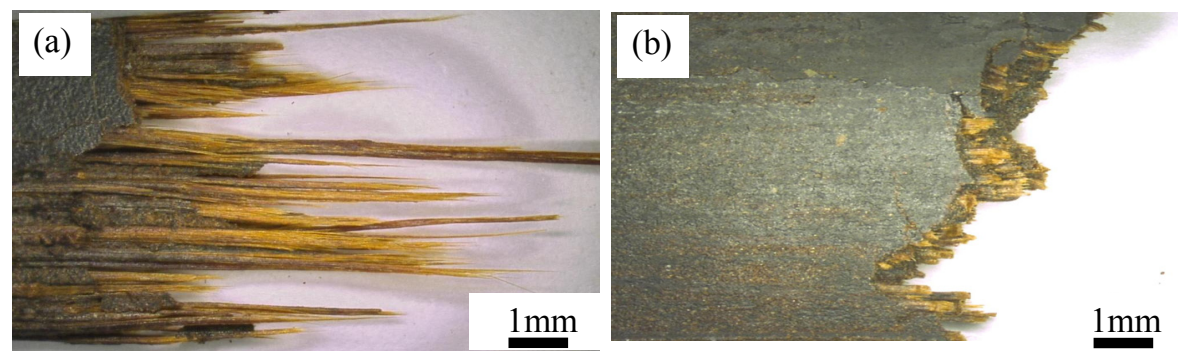

Fig. 6. Fracture aspects of binderless green composites; (a) molded at $120^{\circ} \mathrm{C} / 10 \mathrm{~min} . / 10 \mathrm{MPa}$ and (b) molded at $160^{\circ} \mathrm{C} / 10 \mathrm{~min} . / 10 \mathrm{MPa}$.

The fracture surfaces of the bamboo fiber reinforced binderless green composites molded at $120^{\circ} \mathrm{C}$ and $160^{\circ} \mathrm{C}$ are shown in Fig. 6, showing long pull-out bamboo fiber (Fig. 6(a)) and brittle fracture of bamboo fiber in the composites molded at higher temperature (Fig. 6(b)). This brittle fracture manner is also reported in resinless bamboo composites as well as heat-treated bamboo fiber ${ }^{11}$. 


\section{Conclusions}

Bamboo fiber reinforced binderless green composites were fabricated by using bamboo fiber and steam-exploded bamboo powder, and their mechanical properties were investigated. The major results obtained are summarized as follows:

(i) It can be seen that the stress response of binderless green composites depends on the molding temperature and that there exists a tensile strength peak at $120^{\circ} \mathrm{C}$.

(ii) The drop in tensile strength of binderless green composites molded at higher temperature is closely related to the decrease in tensile strength of bamboo fiber.

(iii) Fracture behavior of binderless green composites is also changed by molding temperature, and brittle fracture mode was observed in the composites molded at higher temperature.

\section{Acknowledgments}

The authors greatly acknowledge the partial financial support provided by The University of Tokushima and Tokushima Prefecture.

\section{References}

1. S. Luo and A. N. Netravali, Polym. Degrad. Stabil. 80, 59 (2003).

2. A. K. Mohanty, M.A. Khan, S. Sahoo and G. Hinrichsen, J. Mater. Sci. 35, 2589 (2000).

3. K. Oksman, L. Wallstrom, L. A. Berglund, F. Toledo and D. Romildo, J. Appl. Polym. Sci. 84, 2358 (2002).

4. A. J. Svagan, M. S. Hedenqvist and L. Berglund, Compo. Sci. Techno. 69, 500 (2009).

5. H. Takagi and Y. Ichihara, JSME Int. J. A-Solid M. 47, 551 (2004).

6. H. Takagi, S. Kako, K. Kusano and A. Ousaka, Adv. Compos. Mater. 16, 377 (2007).

7. H. Takagi and A. Asano, Compos. Part A-Appl. S. 38, 685 (2008).

8. J. K. Pandey, C. S. Lee and S. H. Ahn, J. of Appl. Polym. Sci. 115, 2493 (2010).

9. K. Liu, H. Takagi and Z. Yang, Mater. Design. 275, 247 (2011).

10. H. Takagi and H. Mori, WIT Trans. Built Env. 85, 151 (2006).

11. H. Mori and H. Takagi, in Proc. of Inter. Conf. on Adv. Tech. in Experi. Mechan. (JSME, Fukuoka, 2007) p. OS16-3-2-1.

12. H. Takagi and Y. Okitsu, Mater. Sci. Forum. 675-677, 647 (2011).

13. H. Takagi, Adv. Mater. Res. 275, 247 (2011). 